\title{
ANALISIS USAHATANI CABAI RAWIT DI KECAMATAN SUNGAI RUMBAI KABUPATEN MUKOMUKO
}

\section{(ANALYSIS OF FARMING CAYYENE PEPPERIN SUNGAI RUMBAI DISTRICT, MUKOMUKO DISTRICT)}

\author{
${ }^{1}$ Prasetio Budi, ${ }^{2}$ Novitri Kurniati, SP.M.P, ${ }^{2}$ Ir. Edy Marwan, M.M \\ ${ }^{1}$ Alumni Prodi Agribisnis Faperta UMB \\ Email : prasetiobudiashter@gmail.com \\ ${ }^{2}$ Dosen Prodi Agribisnis Faperta UMB \\ Email : edymarwan.umb@gmail.com
}

\begin{abstract}
This research was done in Sungai Rumbai District, Mukomuko regency, and was conducted in March to April 2019. The study aims to determine the income of cayyene pepper farming, efficieny, feasibilitu study, and production BEP as well as sales BEP in the farmimg in Sungai Rumbai District, Mukomuko Regency. The location of this study was intentionally determined in Sungai Rumbai District, Mukomuko Regency on the consideration that Sungai Rumbai subdistrict is a center of cayyene pepper plantation in Mukomuko regency. Respondents that were involved in this study were 34 cayyene pepper farmers in Sungai Rumbai district of Mukomuko Regency. The data taken were both primary and secondary data. The primary data was directly taken from the farmers by means of interviews, and thr secondary data was taken from related institutians. The results of the analysis of study show that the average income of cayyene pepper farmer was Rp. 13.772.382,36 per planting season. Then the efficiency of R/C Ratio was 2,64 and the feasibility of B/C Ratio was 1,64. The BEP production was $334,65 \mathrm{~kg}$, and sales BEP was Rp. 8.366.352,94 per one production period ( 6 Months).
\end{abstract}

Key Word : income, efficieny, feasibility study, and production BEP as well as sales BEP.

\section{PENDAHULUAN}

Cabai rawit (Capsicum frutescens $L$ merupakan salah satu sayuran yang permintaannya cukup tinggi, baik untuk pasar domestik maupun ekspor ke mancanegara, seperti Malaysia dan Singapura (Sembiring 2009). Selama ini dikenal tiga jenis cabai, yakni cabai merah besar, cabai rawit dan cabai merah keriting. Sebagian besar penduduk Indonesia mengonsumsi cabai dalam bentuk segar, kering atau olahan. Cabai termasuk komoditas unggulan nasional dan sumber vitamin C (Duriat 1995; Kusandriani dan Muharam 2005; Wahyudi dan Tan 2010; Rahmawati et al. 2009). 
Kabupaten Mukomuko merupaka salah satu kabupaten yang ada di Provinsi bengkulu yang berbatasan dengan sumatera barat (Padang). Kabupaten Mukomuko salah satu kabupaten yang masyarakatnya cukup banyak membudidyakan cabai rawit. Untuk tahun 2018 saja Kabupaten Mukomuko memiliki produksi cabai rawit sebesar 545 ton yang tebagi atas 15 kecamaan yang ada.

Di Kabupaten Mukomuko merupakan daerah pengembangan perkebunan sehingga tanaman sayursayuran yang mempunyai peluang sangat sedikit, namun kadang tanaman sayuran mengalami kendala seperti, keterbatasan pengetahuan petani tentang teknologi, keterbatasan lahan, penanaman tergantung musim dan nilai pendapatan petani rendah. Konsep analisis Usahatani ini sekiranya dapat membantu para petani dalam merencanakan laba dan pengendalian aktivitas usaha sehingga kerugian yang menjurus ke arah

Break Even point adalah suatu cara atau teknik yang digunakan oleh para pengambil keputusan di dalam suatu usaha atau bisnis untuk melihat dan mengetahui pada volume berapa banyaknya produksi/penjualan harus dicapai dan harga jual yang harus ditetapkan sehingga impas atau tidak rugi tidak untung.

Oleh karena itu, dilakukan penelitian ini. Yang bertujuan (1) Untuk mengetahui pendapatan usahatani cabai rawit (2) Untuk mengetahui efisiensi usahatani cabai rawit (3) Untuk mengetahui kelayakan usahatani cabai rawit (4) Untuk mengetahui BEP produksi dan BEP penjualan pada usaha tani cabai rawit.

\section{METODE PENELITIAN}

Metode yang akan digunakan dalam penelitian ini yakni menggunakan metode Proportional Random Sampling di mana jumlah sampel pada masing-masing strata sebanding dengan jumlah anggota populasi pada masing-masing stratum populasi (Muri Yusuf, 2014).. Penelitan ini telah dilaksanakan di Kecamatan Sungai Rumbai Kabupaten Mukomuko pada bulan Maret sampai April 2019).

Pendapatan usahatani adalah selisih antara penerimaan dan semua biaya, pernyataan ini dapat di nyatakan dengan umus sebagai berikut.

$$
\begin{aligned}
& \mathrm{Pd}=\mathrm{TR}-\mathrm{TC} \\
& \text { Keterangan : } \\
& \mathrm{Pd}=\text { pendapatan } \\
& \mathrm{TR}=\text { total penerimaan }
\end{aligned}
$$




$$
\mathrm{TC}=\text { total biaya }
$$

Analisis R/C yang dikenal dengan perbandingan antara total penerimaan dan total biaya, dengan menggunakan rumus sebagai berikut :

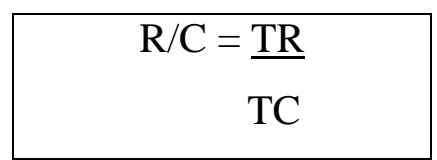

Keterangan :

$\mathrm{TR}=$ total penerimaan

$\mathrm{TC}=$ total biaya

Dengan kriteria :

Jika a > 1, maka usahatani layak untuk diusahakan

Jika a $<1$, maka usahatani tidak layak untuk diusahakan

Jika $\quad \mathrm{a}=1$, maka usahatani layak atau tidak layak untuk diusahakan.

kriteria kelayakan apabila nilai BC Ratio $>1$ sehingga secara teoritis dapat di hitung dengan rumus sebagai berikut :

$\mathrm{B} / \mathrm{C}=\frac{\mathrm{TR}-\mathrm{TC}}{\mathrm{TC}}$

$$
\begin{aligned}
& \text { Keterangan : } \\
& \mathrm{TR}=\text { total penerimaan } \\
& \mathrm{TC}=\text { total biaya }
\end{aligned}
$$

Tingkat break even dapat dilakukan terhadap jumlah barang yang diproduksi atau dijual maupun terhadap besarnya jumlah penghasilan dalam jumlah uang
Dan secara matematis dapat di rumuskan sebagai berikut :

1. BEP Produk

$$
\begin{aligned}
& \mathrm{BEP}=\underline{\mathrm{TC}} \\
& \mathrm{BEP}=\underline{\mathrm{TC}} \\
& \mathrm{P} \\
& \text { Keterangan : } \\
& \mathrm{FC}=\text { Biaya tetap } \\
& \mathrm{P}=\text { penerimaan per unit } \\
& \mathrm{VC}=\text { biaya variabel per unit }
\end{aligned}
$$

2. BEP penjualan

$$
\begin{aligned}
& \text { BEP = BEP produk } x \text { harga } \\
& \text { Keterangan : } \\
& \mathrm{FC}=\text { biaya tetap } \\
& \mathrm{VC}=\text { biaya variabel per unit } \\
& \mathrm{TR}=\text { penerimaan. }
\end{aligned}
$$

\section{HASIL DAN PEMBAHASAN}

Kecamatan Sungai Rumbai ini merupakan salah satu Kecamatan yang berada di Kabupaten Mukomuko Provinsi Bengkulu. Kecamatan Sungai Rumbai terletak di bagian Selatan Kabupaten Mukomuko berjarak $75 \mathrm{Km}$ dari kota Kabupaten Mukomuko dengan Luas wilayahnya mencapai $511,30 \mathrm{~km}^{2}$ yang bebagian besar wilayahnya merupakan perbukitan dengan ketinggian 31 meter di atas permukaan laut (dpl). Yang berbatasan langsung dengan : 
- Sebelah Utara : Kecamatan Pondok Suguh

- Sebelah Selatan : Kecamatan Ipuh

- Sebelah Timur : Provinsi Jambi

- Sebelah Barat : Samudra Hindia

Pendapatan adalah selisih antara total penerimaan dengan total biaya yang di keluarkan dalam satu kali periode produksi usahatani. Total penerimaan usahatani cabai rawit ini yaitu sebesar Rp. 22.138.735,30/satu kali periode usahatani, sedangkan total biaya yang di keluarkan dalam satu kali periode usahatani ini yaitu Rp. 8.366.352,94. Sehingga pendapatan yang di terima oleh petani cabai rawit dalam satu kali periode usaha ini sebesar Rp. 13.772.382,36.

Perhitungan R/C Ratio adalah perbandingan antara penerimaan dengan total biaya yang dikeluarkan selama proses produksi usaha tani cabai rawit di daerah penelitian. Dalam perhitungan ini hanya memasukan nilai produksi rata-rata petani sebesar Rp 22.138.735,30, dan nilai biaya produksi yang dikeluarkan selama proses produksi sebesar Rp 8.366.352,94. Maka nilai $\mathrm{B} / \mathrm{C}$ ratio sebagai berikut:

$$
\begin{aligned}
\mathrm{R} / \mathrm{C} \text { ratio }= & \underline{\mathrm{TR}} \\
& =\frac{22.138 .735,30}{\mathrm{TC}} \\
& 8.366 .352,94 \\
= & 2,64
\end{aligned}
$$

Berdasarkan perolehan perbandingan di atas nilai R/C Ratio sebesar 2,64 yang artinya setiap modal biaya yang di keluarkan dalam usahatani cabai rawit sebesar Rp. 1 akan di peroleh penerimaan sebesar 2,64.

Hal ini menunjukkan perbandingan $\mathrm{R} / \mathrm{C}$ Ratio menghasilkan nilai diatas 1 ( >1), dengan demikian nilai R/C Ratio usahatani cabai rawit di Kecamatan Sungai Rumbai ini artinya usaha tani cabai rawit efisien untuk diusahakan oleh pelaku usahatani cabai rawit.

Hal ini di dukung oleh penelitian Husni, dkk (2014) yang menunjukan nilai Usahatani Cabai Rawit Di Desa Purwajaya Kecamatan Loa Janan dengan nilai R/C Ratio sesbsar 2,07. Selanjutnya Agnes Anita dan Made Antara (2017) yang menunjukan nilai Usahatni Cabai Rawit di Desa Sunju Kecamatan Marawola Kabupaten Sigi dengan nilai R/C sebesar 2,69. Dan di perkuat Yulizar (2015) pada penelitiannya yang menunjukan Usahatani Cabai Merah Di 
Kecamatan Wolya Kabupaten Aceh Barat dengan nilai R/C Ratio sebesar 2,0.

Perhitungan B/C Ratio adalah perbandingan antara pendapatan dengan total biaya yang dikeluarkan selama proses produksi usaha tani cabai rawit di daerah penelitian. Dalam perhitungan ini memasukan nilai produksi rata-rata petani sebesar Rp 22.138.735,30 yang di kurungai dengan nilai biaya produksi yang dikeluarkan selama proses produksi sebesar Rp 8.366.352,94 lalu baru akan di bagi dengan biaya produksi yang dikeluarkan selama proses produksi sebesar Rp 8.366.352,94. Maka nilai B/C ratio sebagai berikut:

$\mathrm{B} / \mathrm{C}$ ratio $=\underline{\mathrm{TR}-\mathrm{TC}}$ $\mathrm{TC}$ $=\underline{22.138 .735,30-8.366 .352,94}$ 8.366.352,94 $=\underline{13.772 .382,36}$ $8.366 .352,94$ $=1,64$

Berdasarkan perolehan perbandingan di atas nilai $\mathrm{B} / \mathrm{C}$ Ratio sebesar 1,64 yang artinya setiap modal biaya yang di keluarkan dalam usahatani cabai rawit sebesar Rp. 1 akan di peroleh keuntungan sebesar 1,64.
Hal ini menunjukkan perbandingan $\mathrm{B} / \mathrm{C}$ Ratio menghasilkan nilai diatas 1 ( >1), dengan demikian nilai $\mathrm{B} / \mathrm{C}$ Ratio usahatani cabai rawit di Kecamatan Sungai Rumbai ini artinya usaha tani cabai rawit layak untuk diusahakan oleh pelaku usahatani cabai rawit.

Pada kondisi saat BEP atau impas menunjukan bahwa penerimaan yang di terima sama dengan total biaya yang di keluarkan. Hasil sari penelitian ini menunjukan hasil dari usahatani cabai rawit ini sebesar 859,41 $\mathrm{kg}$ dengan harga jual yang di terima oleh responden yaitu sebesar Rp. 25.760,38.

Maka BEP produk dan BEP penjualannya adalah :

a. BEP produk

$$
\begin{aligned}
\mathrm{BEP}=\underline{\mathrm{TC}} & =\frac{8.366 .352,94}{25.760,38} \\
& =324,77 \mathrm{~kg}
\end{aligned}
$$

b. BEP penjualan

$$
\begin{aligned}
\mathrm{BEP} & =\mathrm{BEP} \text { produk } \mathrm{x} \text { harga } \\
& =324,77 \times 25.760,38 \\
& =\text { Rp. } 8.366 .352,94
\end{aligned}
$$

Dari hasil perhitungan di atas di ketahui bahwa usahatani cabai rawit di Kecamatan Sungai Rumbai Kabupaten Mukomuko ini mengalami BEP atau titik impas saat produksi yang di hasilkan 
sebesar 324,77 $\mathrm{kg} /$ periode produksi dengan harga jual Rp. 25.760,38/kg.

Pada saat harga jual Rp. 25.760,38/kg dan produksi sebesar 859,41 kg penerimaan usahatani cabai rawit ini adalah sebesar Rp. 22.138.735,30. Pada saat produksi di atas $324,77 \mathrm{~kg} /$ periode produksi maka usahatani cabai rawit ini menguntungkan.

\section{KESIMPULAN}

Berdasarkan hasil penelitian menunjukan bahwa usahatani cabai rawit di Kecamatan Sungai Rumbai ini dapat di simpulakan sebagai berikut :

1. Usahatani cabai rawit di Kecamatan Sungai Rumbai ini menguntungkan dengan pendapatan yaitu sebesar Rp. 13.772.382,36.

2. Usahatani cabai rawit di Kecamatan Sungai Rumbai efisien di usahakan dengan nilai $\mathrm{R} / \mathrm{C}$ sebesar 2,64.

3. Usahatani cabai rawit di Kecamatan Sungai Rumbai ini layak untuk di lakukan dengan nilai $\mathrm{B} / \mathrm{C}$ sebesar 1,64.

4. BEP produk usahatani cabai rawit di Kecamatan Sungai Rumbai ini sebesar $324,77 \mathrm{~kg}$, sedangkan
BEP penjualan usahatani cabai rawit di Kecamatan Sungai Rumbai ini sebesar Rp. 8.366.352,94.

\section{Saran}

1. Disarankan untuk pelaku usahatani cabai rawit di Kecamatan Sungai Rumbai agar untuk lebih meningkatkan produksi di karenakan usahatani cabai rawit ini menguntungkan untuk 1 kali periode penanaman.

2. Disarankan untuk petani cabai rawit di Kecamatan Sungai Rumbai ini agar lebih memperhatikan dalam penggunaan input seperti penambahan pupuk, dan benih yang berkualitas agar produksi usahatani ini meningkat.

3. Untuk pemerintah agar melakukan penyuluhan kepada para pelaku usahatani cabai rawit ini agar tetap berusahatani mengingat penggunaan lahan pertanian semakin tahun semakin menurun.

4. Untuk para peneliti selanjutnya di harapkan agar pada saat melakukan penelitian dengan bantuan kuisioner dapata 
mengambil data secara menyeluruh dan jelas mengingat dalam analisis usahatani rentan dengan adanya data bias.

\section{DAFTAR PUSTAKA}

Agnes. Anita dan Made Antara 2017. Analisis Pendapatan dan Kelayakan Usahatni Cabai Rawit di Desa Sunju Kecamatan Marawola Kabupaten. e-J. Agrotekbis 5 (1) : 86 - 91, Februari 2017

Dinas Pertanian Provinsi Bengkulu. 2019. Luas Panen, Produksi, Produktivitas Tanaman Sayuran Tahun 2017-2018 Kabupaten Mukomuko.

Sembiring. N.N. 2009. Pengaruh Jenis Bahan Pengemas terhadap kualitas produk cabai merah ( Capcisun Annum L ). Tesis Pasca Sarjana. Universitas Sumatra Utara, Medan.

Yulizar. 2015. Analisis Usahatani Cabai Merah di Kecamatan Woyla Kabupaten Aceh Barat. Skripsi Fakultas Pertanian Universitas Teuku Umar Meulaboh Kabupaten Aceh Barat.

Yusuf Muri. 2014. Metode Penelitian : Kuantitatif, Kualitatif, Dan Gabungan Edisi Pertama. PRENADAMEDIA GROUP.

Husni, Abdul Kholik Hidayah, dan Maskan AF. 2014. Analisis Finansial Usahatani Cabai Rawit (Capsicum frutescens $L$ ) Di Desa Purwajaya Kecamatan Loa Janan. Jurnal AGRIFOR Volume XIII Nomor 1, Maret 2014, ISSN : $1412-6885$ 